\title{
Diagnostic Performance of Carbon Monoxide Testing by Pulse Oximetry in the Emergency Department
}

\author{
Nuria Villalba, Zachary T Osborn, Pamela R Derickson, Chelsea T Manning, Robert R Herrington, \\ David A Kaminsky, and Kalev Freeman
}

\begin{abstract}
BACKGROUND: Carbon monoxide (CO) exposure causes roughly 40,000 emergency department (ED) visits annually and is commonly misdiagnosed. Whereas the standard method of carboxyhemoglobin (HbCO) measurement utilizes blood gas analysis, a noninvasive, FDA-cleared alternative exists. We evaluated the performance of pulse oximetry $\left(S_{\mathrm{pCO}}\right)$ for identification of $\mathrm{CO}$ exposure in ED patients. METHODS: We compared pulse oximetry to blood $\mathrm{HbCO}$ levels in a prospective observational study of adult and pediatric subjects recruited from the ED. Nurses screened a convenience sample of patients and referred those with $S_{\mathrm{pCO}} \geq 10 \%$ to research staff. Researchers also approached individuals who presented with signs and symptoms of $\mathrm{CO}$ toxicity. We determined diagnostic performance with a Bland-Altman analysis and calculated sensitivity and specificity for detection of elevated $\mathrm{HbCO}$ at thresholds of $\geq 10 \%$ and $\geq 15 \%$. To optimize the potential sensitivity of $S_{p C O}$ for detection of CO toxicity, research technicians performed $3 \mathrm{~S}_{\mathrm{pco}}$ readings within $5 \mathrm{~min}$ of the blood draw for laboratory measurement. A positive $S_{\mathrm{pco}}$ test was defined as any $S_{\mathrm{pco}} \geq 10 \%$. RESULTS: 42,000 patients were screened, 212 were evaluated, and 126 subjects were enrolled. Median $\mathrm{HbCO}$ level was $6 \%$ (range 1.6-21.9\%). Limits of agreement were $-10.3 \%$ and $8.1 \%$. Of 23 individuals with elevated $\mathrm{HbCO} \geq 10 \%$, 13 were not suspected based on clinical assessment. Critically elevated HbCO was present in 6 individuals. Based on our a priori threshold of $10 \%$ for a positive test, pulse oximetry identified 14 of 23 subjects with $\mathrm{HbCO} \geq 10 \%$, with a sensitivity of $61 \%$ (95\% CI 39-80\%) and a specificity of $86 \%$ (95\% CI 78-92\%), and 5 of 6 subjects with $\mathrm{HbCO} \geq 15 \%$, with a sensitivity of $83 \%$ (95\% CI 36-100\%) and a specificity of $81 \%$ (95\% CI 73-87\%). CONCLUSIONS: Pulse oximetry underestimated $\mathrm{HbCO}$ and produced false negative results (ie, $\mathrm{S}_{\mathrm{pCO}}<10 \%$ for all three measurements) in $17 \%$ of ED subjects with elevated $\mathrm{HbCO} \geq 15 \%$. Triage screening with pulse oximetry detected cases of elevated $\mathrm{HbCO}$ that were not suspected by the clinical provider. Key words: hemoglobin; noninvasive monitor; Masimo Radical-7; carbon monoxide; pulse oximetry; point-of-care. [Respir Care 2019;64(11):1351-1357. (C) 2019 Daedalus Enterprises]
\end{abstract}

\section{Introduction}

Carbon monoxide (CO) exposure causes 40,000 emergency department (ED) visits and 3,000 deaths in the United States each year. ${ }^{1,2}$ Diagnosis of CO toxicity is complicated by non-specific symptoms, and misdiagnosis of $\mathrm{CO}$ toxicity is believed to be common. ${ }^{3}$ The standard method of carboxyhemoglobin $(\mathrm{HbCO})$ measurement is arterial or venous blood

\footnotetext{
Drs Villalba, Freeman, and Herrington, as well as Mr Osborn, Ms Derickson, Ms Manning are affiliated with the Department of Surgery, Larner College of Medicine, University of Vermont, Burlington, Vermont. Dr Kaminsky is affiliated with the Department of Medicine, Larner College of Medicine, University of Vermont, Burlington, Vermont.
}

The authors have disclosed a relationship with Masimo. gas analysis. ${ }^{3,4}$ However, a noninvasive point-of-care device (Radical-7 Pulse CO-Oximeter, MX board version 7.5.0.3, Masimo, Irvine, California) has been cleared by the FDA for $\mathrm{CO}$ measurement via pulse oximetry $\left(\mathrm{S}_{\mathrm{pCO}}\right)$. The Radical-7 pulse oximeter measures the refraction of 8 wavelengths of light through the nail bed using signal-extraction technology pulse oximetry to noninvasively measure $\mathrm{HbCO}$, methemoglobin (Hbmet), oxyhemoglobin, and pulse rate. The objective of this study was to address the limitations of prior stud-

\footnotetext{
Correspondence: Kalev Freeman MD PhD, University of Vermont, 89 Beaumont Ave., Given Building, Room E301, Burlington, VT 05405. E-mail: kalev.freeman@uvm.edu.
}

DOI: $10.4187 /$ respcare. 06365 
ies and to determine the diagnostic performance of this device in the detection of elevated $\mathrm{HbCO}$ under optimal conditions in the ED setting.

\section{See the Related Editorial on Page 1450}

Despite the promise of multi-wavelength pulse-oximetry technology, controversy exists regarding the agreement of the device with standard laboratory testing. ${ }^{5-10}$ Two studies reported relatively wide limitations of agreement with laboratory measurement but concluded that the device has acceptable bias and correlation for screening purposes. ${ }^{5,7}$ Two additional studies reported satisfactory accuracy and precision for screening subjects in the ED. ${ }^{6-8}$ Touger et al ${ }^{8}$ found a bias of $1.4 \%$ but unacceptably wide limits of agreement ( $-11.6 \%$ to $14.4 \%)$, leading them to conclude that $\mathrm{S}_{\mathrm{pCO}}$ could not be used as a substitute for laboratory testing. Both Roth et $\mathrm{al}^{9}$ and Sebbane et $\mathrm{al}^{10}{ }^{10}$ on the other hand, found similar bias but much narrower limits of agreement, prompting them to recommend the technology for screening patients in the ED. Limitations of prior studies included times between $\mathrm{S}_{\mathrm{pCO}}$ measurement and blood draws for laboratory analysis of up to $1 \mathrm{~h}$. Furthermore, the performance of diagnostic tests may vary depending on the magnitude of the abnormal value, and previous studies defined elevated $\mathrm{CO}$ at relatively low levels (eg, $\mathrm{HbCO}$ $>5 \%$ ). These studies may therefore have failed to adequately assess the utility of pulse oximetry for detecting higher $\mathrm{HbCO}$ levels that are more likely to be toxic. ${ }^{9} \mathrm{We}$ hypothesized that the sensitivity of pulse oximetry for detecting blood $\mathrm{HbCO}$ levels $\geq 10 \%$ in patients in the ED setting, under optimal conditions and when performed within a short time interval from the blood test, would be improved relative to previous reports.

We elected to use a multipronged recruitment method to enroll as large a number of true positive (ie, CO-poisoned) patients as possible to determine the performance characteristics of the device for detecting individuals with clinically meaningful CO levels in their blood. We identified patients who presented with either report of a $\mathrm{CO}$ exposure or clinical symptoms consistent with $\mathrm{CO}$ poisoning. We also screened a convenience sample of non-acute ED patients in triage for elevated $\mathrm{S}_{\mathrm{pCO}}$ at a $10 \%$ threshold. We selected this threshold for elevated $\mathrm{HbCO} \geq 10 \%$ not because it represents $\mathrm{CO}$ toxicity, per se, but because it is above the upper limit for the expected physiological range of smokers, even with recent tobacco use. ${ }^{4}$ Therefore, it represents a clinically meaningful $\mathrm{CO}$ elevation in any patient, regardless of the source of $\mathrm{CO}$ exposure. To optimize the potential sensitivity of pulse oximetry to detect elevated $\mathrm{HbCO}, 3$ measurements were obtained by trained research technicians. We limited the elapsed time between blood collection and $\mathrm{S}_{\mathrm{pCO}}$ measurement to $<5 \mathrm{~min}$, thereby

\section{QUICK LOOK}

\section{Current knowledge}

Despite causing roughly 40,000 emergency department visits annually, misdiagnosis of carbon monoxide (CO) exposure is believed to be common due to its nonspecific symptoms. Whereas the standard measurement of carboxyhemoglobin ( $\mathrm{HbCO}$ ) utilizes blood gas analysis, there is a noninvasive, alternative. However, despite noninvasive $\mathrm{CO}$ measurement with pulse oximetry, controversy exists regarding the agreement of the device with standard laboratory testing.

\section{What this paper contributes to our knowledge}

Despite efforts to optimize the performance of pulse oximetry in this study, we found the limits of agreement between pulse oximetry and laboratory measurement comparable to prior studies in subjects recruited from the emergency department. Pulse oximetry underestimated $\mathrm{HbCO}$ overall. Importantly, approximately $17 \%$ of subjects with critically elevated blood $\mathrm{HbCO}$ levels (ie, $\mathrm{HbCO} \geq 15 \%$ ) were missed with the use of pulse oximetry.

eliminating the confounding variable of $\mathrm{CO}$ washout. We prospectively compared the experimental measurement of $\mathrm{HbCO}$ with $\mathrm{S}_{\mathrm{pCO}}$ to the criterion standard, which is laboratory measurement of $\mathrm{HbCO}$ in the blood sample. We compared concurrent $\mathrm{S}_{\mathrm{pCO}}$ and $\mathrm{HbCO}$ measurements with a Bland-Altman plot and report the limits of agreement. We also report diagnostic performance characteristics for this cohort as sensitivity and specificity of a positive test at the $\geq 10 \%$ threshold for the detection of true positive, elevated $\mathrm{HbCO}$ at levels of both $\geq 10 \%$ and $\geq 15 \%$.

\section{Methods}

\section{Study Design and Setting}

We performed a prospective, observational study to determine the diagnostic performance of the $\mathrm{S}_{\mathrm{pCO}}$ sensor in the ED setting under optimal experimental conditions. We enrolled a convenience sample of ED patients suspected of having $\mathrm{CO}$ toxicity and measured $\mathrm{S}_{\mathrm{pCO}}$ and $\mathrm{HbCO}$ concurrently. Our academic ED at the University of Vermont Medical Center in Burlington, Vermont, sees approximately 60,000 patient visits each year. The study was conducted in accordance with the Standards for the Reporting of Diagnostic Accuracy studies, and we obtained local institutional review board approval. ${ }^{11}$ This was an investigator-initiated study supported by the manufacturer of the pulse oximeter (Masimo). The authors designed the study, executed the protocol, per- 
formed the analysis, and wrote the manuscript. None of the authors received any salary or travel funds or were otherwise supported or employed by the sponsor. The role of the sponsor included funding for the technicians and the administrative costs of the study; loaning of the $\mathrm{S}_{\mathrm{pCO}}$ sensors and equipment; and data safety monitoring (ie, review of the institutional review board protocol, training of technicians in use of the sensor, and deployment of study monitors to our site to observe enrollment and data collection). The sponsor did not design the study, collect data, analyze results, or write the manuscript.

\section{Selection of Participants}

A convenience sample of ED patients was screened for this study. Screening was conducted from June 2011 through March 2014 during times when research staff were available. The screening process was designed to identify patients who were most likely to have elevated CO levels. Potential subjects were referred to research staff by ED clinicians. Referring health care providers were instructed to look for patients with a documented $\mathrm{CO}$ exposure or who exhibited signs and symptoms of $\mathrm{CO}$ toxicity. These signs and symptoms included headache, dizziness, nausea, generalized weakness, impaired judgment, confusion, or loss of consciousness. ${ }^{4}$ In addition, triage nurses screened patients with pulse oximetry to identify patients with $\mathrm{S}_{\mathrm{pCO}}$ $\geq 10 \%$ and referred these individuals to research staff for potential enrollment. This method of recruitment was utilized to enrich the study population with additional subjects with potentially elevated $\mathrm{CO}$ levels on the basis of $\mathrm{S}_{\mathrm{pCO}}$, who did not have signs and symptoms of $\mathrm{CO}$ toxicity. Both adult and pediatric patients were eligible for enrollment. Research staff evaluated subject eligibility and obtained written informed consent. Exclusion criteria included patients with Hbmet $>1.6 \%$ as determined with pulse oximetry $\left(\mathrm{S}_{\mathrm{pHbmet}}\right.$ ) because Hbmet interferes with measurement of $\mathrm{S}_{\mathrm{pCO}}$. We also excluded patients with acrylic nails, painted fingernails, or fingernail deformities to avoid interference with $\mathrm{S}_{\mathrm{pCO}}$ measurement.

\section{Interventions}

Research staff were trained by the manufacturer and investigators in proper use of the device. Research nurses were also trained to measure $\mathrm{S}_{\mathrm{pCO}}$ as part of routine triage of ambulatory patients, when time and staffing permitted this assessment. A representative of the manufacturer visited the ED on a quarterly basis to monitor device use and re-train research personnel.

\section{HbCO Measurements}

Upon enrollment of a subject, venous blood was drawn and measurement of $\mathrm{HbCO}$ was performed by an accred- ited, in-hospital laboratory using a Sysmex XN9000 hematology analyzer (Sysmex America, Lincolnshire, Illinois). This blood $\mathrm{HbCO}$ measurement is considered the criterion standard measure. The laboratory was blind to $\mathrm{S}_{\mathrm{pCO}}$ levels, and research staff were blind to $\mathrm{HbCO}$ results at the time of $\mathrm{S}_{\mathrm{pCO}}$ measurement. Trained research staff performed $\mathrm{S}_{\mathrm{pCO}}$ measurement as close to the time of blood draw as possible, from the contralateral arm, and never during tourniquet or blood pressure cuff use. For $\mathrm{S}_{\mathrm{pCO}}$ measurements, a Rainbow R 125 adult adhesive sensor connected to a Radical-7 Pulse CO-Oximeter was placed on the middle finger of the non-dominant hand and covered with an opaque probe cover to eliminate interference from ambient light. The manufacturer recommends $3 \mathrm{~S}_{\mathrm{pCO}}$ readings to improve accuracy in cases of unexpectedly high $\mathrm{S}_{\mathrm{pCO}}$ (Radical-7 Signal Extraction Pulse CO-Oximeter Operator's Manual, pp. 6-1, Available at http://www.infiniti.no/upload/ Bruksanvisningar/Masimo/MAS_UM_EN_Radical7\%20Color\%20Display\%20Operators\%20Manual.pdf). We performed 3 readings in all cases for consistency, regardless of the $\mathrm{S}_{\mathrm{pCO}}$ level. We only included measurements taken within $5 \mathrm{~min}$ before or after the blood draw for analysis. Subject demographic data were collected from the electronic medical record. Study data were collected and managed using REDCap (Research Electronic Data Capture), a secure, web-based application designed to support data capture for research studies. ${ }^{12}$

\section{Outcomes}

To determine performance characteristics across the range of $\mathrm{HbCO}$ values, we calculated the average of the $3 \mathrm{~S}_{\mathrm{pCO}}$ values for each individual subject and compared this to the criterion standard of the blood $\mathrm{HbCO}$ with a Bland-Altman analysis. For sensitivity and specificity calculations, we defined a positive pulse-oximeter signal as any of $3 \mathrm{~S}_{\mathrm{pCO}}$ readings $\geq 10 \%$. While some trials have utilized different thresholds for smokers and non-smokers, we used the criterion standard of elevated $\mathrm{HbCO}$ as blood $\mathrm{HbCO} \geq 10 \%$ for all subjects because this is outside of the expected physiological range for smokers. ${ }^{4}$ As a secondary analysis, we also evaluated the sensitivity and specificity of the pulse oximeter to detect the outcome of critically elevated $\mathrm{HbCO}$, defined as levels of blood $\mathrm{HbCO}$ $\geq 15 \%$. This threshold was based on a study in which 10 healthy controls exhibited no unpleasant symptoms or significant changes in vital signs with $\leq 15 \%$ HbCO. ${ }^{13}$

\section{Statistical Analysis}

Demographic data were summarized with proportions and with medians and interquartile ranges. We plotted mean versus difference and calculated limits of agreement between the measurements as described by Bland and 


\section{Detection of HbCO by Pulse Oximetry}

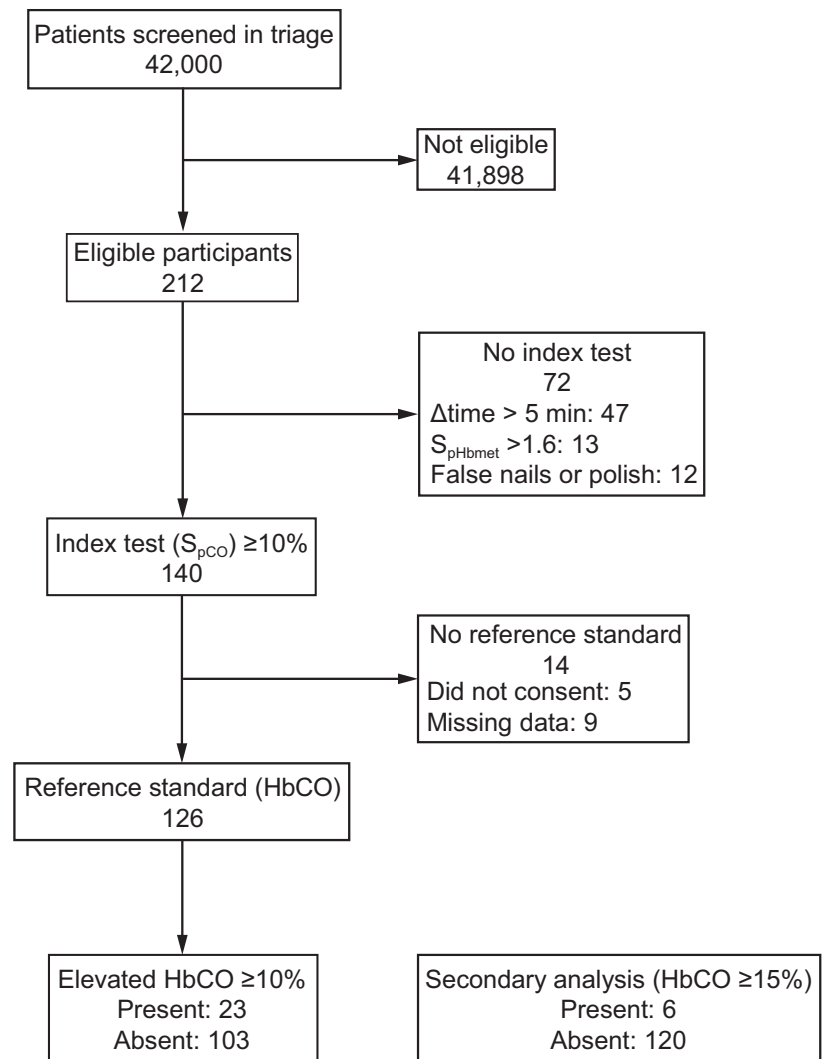

Fig. 1. Flow chart.

Altman, showing the mean of the differences between methods $\pm 1.96 \mathrm{SD}$ above and below the mean. ${ }^{14,15}$ Other measures, including repeatability and confidence intervals for bias and limits of agreement, are reported as recommended by Chhapola et al ${ }^{16} \mathrm{We}$ determined the diagnostic performance for detection of elevated and critically elevated $\mathrm{HbCO}$ according to our a priori outcome criteria. Sensitivity and specificity were calculated with the $95 \%$ CIs for the noninvasive hemoglobin measurement $\left(\mathrm{S}_{\mathrm{pCO}}\right)$ to detect the criterion laboratory measurement (HbCO) at levels of $\geq 10 \%$ and $\geq 15 \%$. Statistical analyses were performed with Microsoft Excel (Microsoft, Redmond, Washington), and graphs were produced with GraphPad Prism 7 (GraphPad Software, La Jolla, California).

\section{Results}

\section{Characteristics of Study Subjects}

Of approximately 42,000 patients screened by clinical staff during those times when research staff were present, 212 patients were identified by either clinical signs and symptoms or $\mathrm{S}_{\mathrm{pCO}}$ as potential subjects likely to have elevated $\mathrm{HbCO}$ (Fig. 1). Of these, 207 provided informed
Table 1. Subject Characteristics

\begin{tabular}{lcc}
\hline \hline & $\begin{array}{c}\text { Included } \\
\text { Subjects }\end{array}$ & $\begin{array}{c}\text { Excluded } \\
\text { Subjects }\end{array}$ \\
\hline Age, y & $36(27-52)$ & $38(28-54)$ \\
Male & $69(54.8)$ & $25(34.7)$ \\
Caucasian & $119(95.2)$ & $67(93.1)$ \\
Temperature $>38^{\circ} \mathrm{C}$ & $4(3 \%)$ & $0(0 \%)$ \\
Heart rate $>100$ beats/min & $13(10 \%)$ & $4(5 \%)$ \\
$\mathrm{HbCO} \%$ & $6.0(4.2-9.2)$ & $4.9(4.1-7.2)$ \\
$\mathrm{S}_{\mathrm{pCO}} \%$ & $5.3(2.9-8.0)$ & $4.1(1.9-7.5)$ \\
$\mathrm{S}_{\mathrm{pHbmet}} \%$ & $0.4(0.7-1.1)$ & $1(0.7-1.5)$ \\
Suspicious symptoms (eg, headache, & $72(57 \%)$ & $41(58 \%)$ \\
$\quad$ nausea, dizziness, generalized & & \\
$\quad$ weakness, impaired judgement, & & \\
$\quad$ confusion, exposure to fire) & $15(13.6)$ & $6(11)$ \\
Treated with oxygen therapy & $1(0-3)$ & $8.5(3-20)$ \\
Time between blood sample and & & \\
$\quad$ cooxymetry reading, min & & \\
& & \\
\hline$N=198$ subjects (126 included subjects; 72 excluded subjects). \\
Data are shown as $n$ (\%) or median (interquartile range). \\
\hline
\end{tabular}

consent. Twelve were excluded for acrylic or polished nails, 13 for $S_{\text {pHbmet }}>1.6$, and 47 because $>5 \mathrm{~min} \mathrm{had}$ elapsed between measurements. Nine subjects were missing either $\mathrm{HbCO}$ or $\mathrm{S}_{\mathrm{pCO}}$ data and were not analyzed. Thus, a total of 126 subjects were included in the analysis. Subjects ranged in age from 15 y to 89 y and reported a wide variety of chief complaints, such as fever, chest or abdominal pain, or trauma. Included subjects and excluded patients had similar demographic and clinical characteristics except for sex: $54.8 \%$ of included subjects and $34.7 \%$ of excluded patients were male (Table 1).

\section{Statistical Analysis}

Of the 126 subjects analyzed, the range of $\mathrm{HbCO}$ levels was $1.6-21.9 \%$ with a median of $6.0 \%$ (interquartile range 4.2-9.2\%). The $\mathrm{S}_{\mathrm{pCO}}$ readings for these subjects ranged from 0 to $23.6 \%$ with a median of $5.3 \%$ (interquartile range $2.9-8.0 \%$ ). For quantitative comparison of $\mathrm{S}_{\mathrm{pCO}}$ to $\mathrm{HbCO}$, we used the average of the $3 \mathrm{~S}_{\mathrm{pCO}}$ readings for each individual. The scatter plot of $\mathrm{HbCO}$ versus $\mathrm{S}_{\mathrm{pCO}}$ showed a weak positive relationship $(\mathrm{r}=0.292, P<.001)$ (Fig. 2). The mean difference plot (Fig. 3) showed no evidence of heteroscedasticity (differences in magnitude proportional to the size of the measurements). $\mathrm{S}_{\mathrm{pCO}}$ was most often an underestimation of $\mathrm{HbCO}$ level, as shown by the calculated bias of $-1.1 \%$ for the mean difference $\left(\mathrm{HbCO}-\mathrm{S}_{\mathrm{pCO}}\right)$. The limits of agreement from BlandAltman analysis were $-10.3 \%$ to $8.1 \%$ (Table 2).

We determined the sensitivity and specificity of positive $\mathrm{S}_{\mathrm{pCO}}$ (defined a priori as any of 3 measurements $\geq 10 \%$ ) for detection of elevated $\mathrm{HbCO}$. On the basis of the diag- 


\section{Detection of HbCO by Pulse Oximetry}



Fig. 2. Scatterplot of laboratory $\mathrm{HbCO}$ vs pulse oximetry $\mathrm{S}_{\mathrm{pcO}}$ readings.

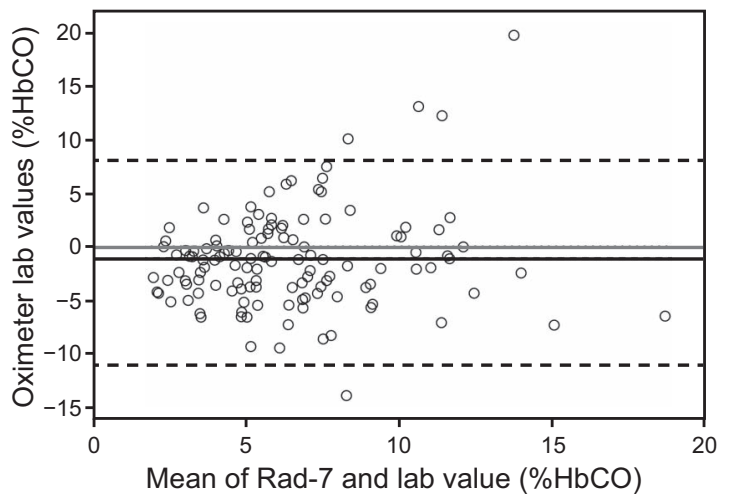

Fig. 3. Bland-Altman plot of difference against mean for $\mathrm{HbCO}$ and $\mathrm{S}_{\mathrm{pco}}$ readings.

Table 2. Bland-Altman Bias and Limits of Agreement

\begin{tabular}{lc}
\hline \hline & Estimate $(95 \% \mathrm{CI})$ \\
\hline Bias (mean difference) & $-1.1 \%(-1.9 \%$ to $0.3 \%)$ \\
Limit of agreement (upper) & $8.1 \%(7.4 \%$ to $8.8 \%)$ \\
Limit of agreement (lower) & $-10.3 \%(-11.0 \%$ to $-9.6 \%)$ \\
\hline
\end{tabular}

nostic criterion of elevated $\mathrm{HbCO} \geq 10 \%$, our cohort of 126 individuals consisted of 23 true positives and 103 true negatives (Table 3 ). $\mathrm{S}_{\mathrm{pCO}}$ was positive in 14 of the 23 true positive subjects, with 9 false negatives (sensitivity $61 \%$ [95\% CI 39-80\%]); $\mathrm{S}_{\mathrm{pCO}}$ was negative in 89 of 103 true negative subjects, with 14 false positives (specificity $86 \%$ [95\% CI 78-92\%]). Of these 23 individuals with blood levels of $\mathrm{HbCO} \geq 10 \%, 10$ were suspected by the treating clinicians to have $\mathrm{CO}$ toxicity ( 4 had a known exposure and 6 had symptoms indicating possible CO toxicity). On the other hand, 13 individuals had neither symptoms nor a known exposure and might therefore be considered "occult" CO toxicity. We also determined the sensitivity and specificity for detection of critically elevated $\mathrm{HbCO}$ de-
Table 3. Sensitivity and Specificity of Pulse Oximeter in Detection of Elevated Blood $\mathrm{HbCO}$ at the Criterion Standards

\begin{tabular}{lrrr}
\hline \hline Blood $\mathrm{HbCO} \geq 10 \% *$ & & & \\
Cooximeter & + & - & Total \\
+ & 14 & 14 & 28 \\
- & 9 & 89 & 98 \\
Total & 23 & 103 & 126 \\
Blood HbCO $\geq 15 \% \dagger$ & & & \\
Cooximeter & + & - & Total \\
+ & 5 & 23 & 28 \\
- & 1 & 97 & 98 \\
Total & 6 & 120 & 126
\end{tabular}

$*$ Sensitivity $=61 \%(39 \%-80 \%)$; specificity $=86 \%(78-92 \%)$.

$\dagger$ Sensitivity $=83 \%(36-100 \%)$; specificity $=81 \%(73-87 \%)$.

fined as levels $\geq 15 \%$. At this threshold, the sensitivity of $\mathrm{S}_{\mathrm{pCO}}$ was $83 \%$ (95\% CI 36-100\%) and the specificity was $81 \%(73-87 \%)$ (Table 3).

We performed a pre-planned sensitivity analysis to determine the extent of bias that might have been introduced by dropping subjects in whom $\mathrm{S}_{\mathrm{pCO}}$ could not be obtained or who were excluded for other reasons. Thus, we compared the demographic characteristics and $\mathrm{HbCO}$ levels in the 72 subjects who were excluded to the 126 who were analyzed (Table 1). The $\mathrm{HbCO}$ in the excluded subjects averaged $5.4 \%$ (SD 5.2\%), which was not significantly different from those subjects who were included. Of note, one dropped subject with a known $\mathrm{CO}$ exposure and critically elevated $\mathrm{HbCO}$ level of $20.5 \%$ was missed by the device, which incorrectly reported elevated $\mathrm{S}_{\mathrm{pHbmet}}$ and normal $\mathrm{S}_{\mathrm{pCO}}$. Another subject with a $\mathrm{HbCO}$ level of $15.3 \%$ also escaped detection, likely due to acrylic nail polish. Elevated $\mathrm{S}_{\mathrm{pHbmet}}$ and nail polish were a priori exclusion criteria, so these individuals were not included in the primary analysis.

We performed 3 readings in all cases, regardless of $\mathrm{S}_{\mathrm{pCO}}$ level. However, the manufacturer's operations manual recommends taking the average of 3 readings to improve accuracy only in cases of unexpectedly high $\mathrm{S}_{\mathrm{pCO}}$. An $\mathrm{S}_{\mathrm{pCO}}$ reading was considered "unexpectedly high" if the subject was not previously suspected of exposure to CO. In normal clinical use, it is therefore more likely that only a single measurement would be performed. We attempted to simulate this by re-analyzing the sensitivity and specificity for the first reading only. In a mean difference analysis of first measurements only, bias was slightly smaller $(-0.8 \%)$ and limits of agreement widened slightly to $-10.4 \%$ to $8.7 \%$. Because 2 subjects with blood levels $\geq 10 \%$ were only identified on the second or third $\mathrm{S}_{\mathrm{pCO}}$ reading, use of the first reading only produced a lower sensitivity of 52\% (31-73\%) with a specificity of $88 \%(81-94 \%)$. 


\section{Detection of HbCO by Pulse Oximetry}

\section{Discussion}

Venous blood oximetry is accurate and precise, but phlebotomy is invasive and blood analysis requires time and a credentialed laboratory. Pulse oximetry offers a point-ofcare alternative to rapidly screen for elevated $\mathrm{HbCO}$ without drawing blood. The diagnostic performance of pulse oximetry for the detection of elevated $\mathrm{HbCO}$ in the ED is controversial. We identified 3 studies that evaluated pulse oximetry technology by comparing $\mathrm{S}_{\mathrm{pCO}}$ to the accepted standard of laboratory measurement and which met Standards for Reporting of Diagnostic Accuracy and reported agreement using Bland and Altman's approach. ${ }^{8-11}$ Touger et $\mathrm{al}^{8}$ studied $120 \mathrm{ED}$ subjects with a suspected diagnosis of $\mathrm{CO}$ toxicity and reported limits of agreement from a Bland-Altman analysis of $-11.6 \%$ and $14.4 \% \mathrm{HbCO}$. The authors defined the a priori threshold as agreement $<5 \%$ $\mathrm{HbCO}$ and concluded that $\mathrm{S}_{\mathrm{pCO}}$ measurement may not be used interchangeably with laboratory measurement. Later, Roth et $\mathrm{al}^{9}$ studied a larger sample of 1,500 unselected subjects in the ED and reported slightly better limits of agreement of -3.6 to $9.5 \mathrm{HbCO}$. They concluded that $\mathrm{S}_{\mathrm{pCO}}$ measured $\mathrm{HbCO}$ with acceptable bias and precision. However, they identified only 17 subjects with $\mathrm{CO}$ poisoning, which was defined clinically and included nonsmokers with levels of $\mathrm{HbCO}$ that were $<10 \%$. In addition, their $\mathrm{S}_{\mathrm{pCO}}$ measurements were made within $60 \mathrm{~min}$ of the $\mathrm{HbCO}$ measurement. Sebbane et $\mathrm{al}^{10}$ reported on 93 subjects with suspected $\mathrm{CO}$ toxicity, including 26 with $\mathrm{CO}$ poisoning (defined as blood $\mathrm{HbCO}>5 \%$ for non-smokers and $>10 \%$ for smokers), and found limits of agreement of $-6.7 \%$ and $6.3 \%$. Measurements were made within a mean of 19 min (95\% CI $10-29 \mathrm{~min}$ ).

We attempted to improve on previous studies in several ways. We utilized a dedicated research team to recruit ED subjects who were suspected of having $\mathrm{CO}$ toxicity. We identified clinically meaningful levels of $\mathrm{HbCO} \geq 10 \%$ for elevated and $\geq 15 \%$ for critically elevated for all $\mathrm{CO}$ exposures, including tobacco and other causes. We excluded measurements made $>5 \mathrm{~min}$ apart to reduce the effect of $\mathrm{CO}$ washout between measurements. We worked with representatives from the manufacturer to ensure ideal training, technique, and equipment function. We also conducted $3 \mathrm{~S}_{\mathrm{pCO}}$ measurements in each case, using the average of the 3 for Bland-Altman analysis, and we used any reading $>10 \%$ as our definition of a positive test for sensitivity and specificity analysis. These efforts produced a rigorous set of experimental data, including subjects with a range of $\mathrm{CO}$ levels, but the performance characteristics of pulse oximetry were not better than in previous studies.

Our sensitivity analysis resulted in only slight changes in the main results. Re-analysis using only $1 \mathrm{~S}_{\mathrm{pCO}}$ reading yielded slightly lower sensitivity and slightly higher specificity. Bias slightly decreased in magnitude, but at the cost of wider limits of agreement. Including all excluded subjects (eg, artificial nails, nail polish, $\mathrm{S}_{\mathrm{pHbmet}}>1.6 \%$, and $>5$ min elapsed between methods) again revealed a slightly smaller bias but wider limits of agreement that did not appear substantially different from the restricted dataset. One subject who was excluded due to elevated $\mathrm{S}_{\mathrm{pHbmet}}$ and had a $\mathrm{HbCO}$ level of $20.5 \%$ warrants discussion. This individual was symptomatic, and blood analysis confirmed elevated $\mathrm{HbCO}$ without Hbmet elevation, but the device missed this diagnosis, reporting $\mathrm{S}_{\mathrm{pHbmet}}$ elevation with normal $\mathrm{S}_{\mathrm{pCO}}$ on multiple measurements. Thus, clinicians should be aware of the potential for oximetry to incorrectly suggest methemoglobinemia in some $\mathrm{CO}$ toxicity cases.

The relative infrequency of elevated $\mathrm{HbCO}$ levels among the large number of potentially eligible subjects is a limitation. It is difficult to identify subjects while they still have high $\mathrm{HbCO}$ levels, in part because the half-life of carbon monoxide, even with room air, is $<3 \mathrm{~h}$. It often takes minutes to hours to capture and consent ED patients with $\mathrm{CO}$ toxicity, and by this time their blood levels may start to decline. Furthermore, although $\mathrm{S}_{\mathrm{pCO}}$ measurements occurred within 5 min of the blood draw, the elapsed time between the draw and the measurement of $\mathrm{HbCO}$ in the blood sample by the hospital's accredited laboratory was not recorded. It is possible that $\mathrm{HbCO}$ levels within the sample could have changed during this time period.

Although we conducted $3 \mathrm{~S}_{\mathrm{pCO}}$ measurements for all subjects, it is unlikely that this would occur in most clinical applications. Our sensitivity analysis found that when we used only the first of $3 \mathrm{~S}_{\mathrm{pCO}}$ measurements, sensitivity dropped to only $52 \%$ (95\% CI 31-73\%). Relatively small numbers of true positives result in wide confidence intervals for sensitivity and specificity of the device. We therefore intentionally used a strategy to enrich our sample for subjects most likely to include true positives, enrolling specifically those subjects who were suspected to have $\mathrm{CO}$ toxicity due to report of an exposure, clinical symptoms, or $\mathrm{S}_{\mathrm{pCO}}$ screening levels. This sampling strategy itself has limitations. Among these is the possibility that the subjects recruited from triage may be intrinsically different than those recruited via clinician referral.

We used a threshold of $\mathrm{HbCO} \geq 10 \%$ as the upper limit of normal cutoff for screening for elevated $\mathrm{HbCO}$ in all subjects with or without smoking history. In clinical practice, $\mathrm{HbCO}$ levels $>4 \%$ in non-smokers and $>10 \%$ in smokers can be considered outside the normal physiological range. ${ }^{4}$ Two previous studies, one with a cutoff of $6.6 \% \mathrm{HbCO}$ for all subjects and the other with cutoffs of $9 \%$ for smokers and $6 \%$ for non-smokers, reported the best combination of sensitivity and specificity for use as a screening tool for $\mathrm{CO}$ poisoning. ${ }^{9,10} \mathrm{We}$ settled on a single-criterion standard for elevated $\mathrm{HbCO}$ of blood $\mathrm{HbCO}$ $\geq 10 \%$ because it falls outside of the physiological range for both smokers and non-smokers and because the source 
of $\mathrm{CO}$ exposure is important in clinical management but irrelevant to the performance of the assay. ${ }^{4}$ Regardless of the threshold that may be applied, the Bland-Altman analysis provides an estimate of performance characteristics and allows comparison between the different studies, independent of thresholds used for the criterion diagnosis. We did not define a priori accepted Bland-Altman limits of agreements, however our limits did fall outside the previously defined $<5 \% \mathrm{HbCO}$ a priori limits established by Touger et al. ${ }^{8}$

It should be noted that our study was not designed to test the utility of the device for triage screening of all patients presenting to the ED triage. To assess utility for triage screening, blood testing would need to be performed on all of the 42,000 potentially eligible patients who were screened. This was beyond the scope of our study. That being said, our results offer conflicting clues as to the efficacy of the device in such an application. On the one hand, pulse oximetry returned false negatives for $39 \%$ of subjects with $\mathrm{HbCO} \geq 10 \%$. This figure fell to $17 \%$ of subjects above the critically elevated threshold of $\mathrm{HbCO}$ $\geq 15 \%$. On the other hand, we did identify 13 individuals with elevated $\mathrm{CO}$ levels without symptoms or a known exposure. This suggests ED triage screening with pulse oximetry has utility in identification of some individuals with occult $\mathrm{CO}$ poisoning.

\section{Conclusion}

Despite efforts to optimize the performance of pulse oximetry in this study, we found the limits of agreement between pulse oximetry and laboratory measurement of $-10.3 \%$ and $8.1 \%$, which were comparable to prior studies in subjects recruited from the ED. $\mathrm{S}_{\mathrm{pCO}}$ slightly underestimated $\mathrm{HbCO}$ overall with a bias of $-1.1 \%$.

Although our study was not specifically designed to evaluate the role of pulse oximetry in triage, we noted that triage screening of ED patients with pulse oximetry identified $\mathrm{CO}$ exposure in approximately $0.05 \%$ of patients, about half of whom might have been missed by clinical assessment alone. Future studies that include blood measurements in all eligible subjects are needed to determine the utility of this device as a screening tool. The sensitivity and specificity results we provide for detection of $\mathrm{HbCO}$ at clinically important thresholds should aid clinicians seeking to use $\mathrm{S}_{\mathrm{pCO}}$ for medical decision-making in the ED setting.

\section{REFERENCES}

1. Hampson NB. Emergency department visits for carbon monoxide poisoning in the Pacific Northwest. J Emerg Med 1998;16(5):695-698.

2. Centers for Disease Control and Prevention (CDC). Carbon monoxide-related deaths: United States, 1999-2004. MMWR Morb Mortal Wkly Rep 2007;56(50):1309-1312.

3. Wolf SJ, Lavonas EJ, Sloan EP, Jagoda AS. Clinical policy: critical issues in the management of adult patients presenting to the emergency department with acute carbon monoxide poisoning. Ann Emerg Med 2008;51(2):138-152.

4. Hampson NB, Piantadosi CA, Thom SR, Weaver LK. Practice recommendations in the diagnosis, management, and prevention of carbon monoxide poisoning. Am J Respir Crit Care Med 2012;186(11): 1095-1101.

5. Suner S, Partridge R, Sucov A, Valente J, Chee K, Hughes A, et al. Non-invasive pulse CO-oximetry screening in the emergency department identifies occult carbon monoxide toxicity. J Emerg Med 2008; 34(4):441-450.

6. O'Malley GF. Non-invasive carbon monoxide measurement is not accurate. Ann Emerg Med 2006;48(4):477-478.

7. Piatkowski A, Ulrich D, Grieb G, Pallua N. A new tool for the early diagnosis of carbon monoxide intoxication. Inhal Toxicol 2009; 21(13):1144-1147.

8. Touger M, Birnbaum A, Wang J, Chou K, Pearson D, Bijur P. Performance of the RAD-57 pulse co-oximeter compared with standard laboratory carboxyhemoglobin measurement. Ann Emerg Med 2010;56(4):382-388.

9. Roth D, Herkner H, Schreiber W, Hubmann N, Gamper G, Laggner AN, et al. Accuracy of noninvasive multiwave pulse oximetry compared with carboxyhemoglobin from blood gas analysis in unselected emergency department patients. Ann Emerg Med 2011;58(1):74-79.

10. Sebbane M, Claret PG, Mercier G, Lefebvre S, Thery R, Dumont R, et al. Emergency department management of suspected carbon monoxide poisoning: role of pulse CO-oximetry. Respir Care 2013;58(10): 1614-1620.

11. Bossuyt PM, Reitsma JB, Bruns DE, Gatsonis CA, Glasziou PP, Irwig LM, et al. Towards complete and accurate reporting of studies of diagnostic accuracy: the STARD initiative. Fam Pract 2004;21(1):4-10.

12. Harris PA, Taylor R, Thielke R, Payne J, Gonzalez N, Conde JG. Research electronic data capture (REDCap)-a metadata-driven methodology and workflow process for providing translational research informatics support. J Biomed Inform 2009;42(2):377-381.

13. Barker SJ, Curry J, Redford D, Morgan S. Measurement of carboxyhemoglobin and methemoglobin by pulse oximetry: a human volunteer study. Anesthesiology 2006;105(5):892-897.

14. Bland JM, Altman DG. Measuring agreement in method comparison studies. Stat Methods Med Res 1999;8(2):135-160.

15. Bland JM, Altman DG. Agreement between methods of measurement with multiple observations per individual. J Biopharm Stat 2007;17(4):571-582.

16. Chhapola V, Kanwal SK, Brar R. Reporting standards for BlandAltman agreement analysis in laboratory research: a cross-sectional survey of current practice. Ann Clin Biochem 2015;52(Pt 3):382-386.

This article is approved for Continuing Respiratory Care Education credit. For information and to obtain your CRCE

(free to AARC members) visit www.rcjournal.com

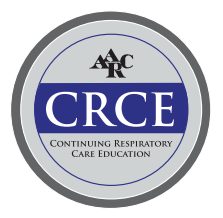

